\title{
Effectiveness of an intervention on verbal violence among students with intellectual disabilities
}

\author{
Nirit Karni \\ Department of Special Education, University of Haifa, Haifa, Israel
}

Email address:

niritkarni2@gmail.com

\section{To cite this article:}

Nirit Karni. Effectiveness of an Intervention on Verbal Violence among Students with Intellectual Disabilities. International Journal of Secondary Education. Vol. 2, No. 5, 2014, pp. 87-93. doi: 10.11648/j.ijsedu.20140205.11

\begin{abstract}
This article focus on verbal violence among students with intellectual disabilities (ID). The purpose of the research was to assess the impact of an intervention program based on the model of the "Cycle of Internalized Learning" (Reiter, 2008), on the reduction of verbal violence and to find out if there are gander differences in the use of verbal violence. The sample consisted of 44 students with ID attending 5 classrooms. Three classrooms were the experimental group $(\mathrm{N}=20)$ and two classes were the comparison group $(\mathrm{N}=24)$. Pre - post method was applied, all participant filled in a bullying questionnaire (Olweus, 1993). The experimental group underwent intervention. The findings revealed that the intervention program was effective in decreasing the use of verbal violence. Concerning gander, there were no significant differences between boys and girls, although the girls had greater tendency to use verbal violence then the boys. The results provide information that contribute to the understanding of patterns of verbal violence among students with ID and in the design of future intervention programs.
\end{abstract}

Keywords: Intellectual Disability, Verbal Violence, Intervention Program

\section{Introduction}

There is a great concern being expressed around the world about violence against children, in general, and particularly its emergence in school settings. School violence endangers the safety of students and teachers and undermines the educational achievement. Many attempts are being made to study the issue of violence and identify effective practices to reduce and prevent it from occurring (Balin-Arcaro, Smith, Cunningham, Vaillancourt, \& Rimas, 2012; Benbenishty, Astor \& Marachi, 2007). Students are exposed to many types of violence, including physical harm, verbal harm, and aggressive interpersonal relationships (i.e., bullying), experienced either directly or indirectly (e.g., the spreading of rumors, isolation, gossip, etc.) (Balin-Arcaro, et al., 2012; Craig \& Pepler, 2007; Lund et al., 2012; Sherer \& Nickerson, 2010). Olweus was a pioneer in the study of school violence. In 1985 he estimated that $15 \%$ of $1^{\text {st }}-12^{\text {th }}$ grade students in Norway were involved in violence either as the aggressor or victim, or both (Olweus, 1991). Following the findings of his research, other researchers around the world began to investigate the phenomenon and found that similar rates (10 $-20 \%$ ) of students were involved in violence (Liang et al.,
2007; Nansel, et al., 2003; Estell, Farmer, Irvin, Crowther, Akos \& Boudah, 2009; Sherer \& Nickerson, 2010). Some research has shown that the rates of involvement in physical violence is higher for boys than for girls, who are more involved in verbal violence (Balin-Arcaro, et al., 2012; Eaton, Kann, Kinchen, Shanklin, Ross, Hawkins, Harris \& Lowry, 2008), while other studies have found no differences (Benbenishty \& Astor, 2005; Krakowski \& Czobor, 2004).

More recently, investigators have become interested in examining school violence in special education settings (Carter \& Spencer, 2006; Reiter, Bryen, \& Shachar, 2007). Reiter \& Lapidot-Lefler (2007) investigated violence in special schools for students with intellectual disabilities (ID) and found ample evidence of physical aggression such as pushing and beatings, as well as verbal aggression. Verbal violence is defined as any use of language whose aim is to intimidate, frighten, or harm by yelling or swearing, engaging in name calling, or using other words whose intent is to control or hurt (Uzun, 2003). While physical violence is easily identified because one can actually see the marks it leaves, verbal violence is more likely unseen and undetected. Some, downplay verbal violence as a 'bad habit' or as an 'allowed' expression of 'anger' or 'bad 
temper' or 'just the way the person talks' (Bernes \& Bardick, 2007). It can be disguised as jokes, harsh criticism, or as minor belittling. Evans $(2010 ; 2012)$ pointed out in his research that the frequency of verbal violence is on the rise. Verbal violence is believed to be particularly important as it is thought of as a precedent to episodes of physical violence in one of two ways. First, the aggressor may become physically violent following episodes of verbal violence. Second, the victim of verbal violence may retaliate physically to verbal insults. Students with ID may be at heightened risk for verbal violence (Carter \& Spencer, 2006). Despite the importance of the issue, verbal violence has not yet been investigated among the general student population or in particular among students with special needs. And there are no published studies of intervention programs in this area.

This study focuses on students with ID. Intellectual disability is a disability characterized by significant limitations in both intellectual functioning and adaptive behavior, which covers everyday social and practical skills. This disability originates before the age of 18 (Schalock, et al., 2010).

Interventions have been developed that target physical violence among individuals with ID. Sigafoos et al., (1994) reviewed aggressive behavior among 2,412 individuals with ID in Australia. Thirty-five percent were involved in at least one form of aggressive behavior. Two-thirds of those who were involved in aggressive behavior were given drugs to reduce this behavior, while the remaining third took part in a behavioral modification program. The behavioral program was effective in reducing aggression, indicating that non-pharmacological interventions can be effective. The program's "second step" (Grossman et al., 1997) was also found to effectively reduce violence among students by helping them to achieve new thinking habits and eliminate old, problematic, learned behaviors. The program aims to strengthen positive behavior by fostering skills and creating positive social relationships and acquiring skills that enable interpersonal conflict solutions and resolution among members of the classroom. In another study, Ross et al., (2000) conducted a group intervention program aimed at reducing expressions of anger among students with developmental disabilities. All 25 individuals had a history of physical violence, damage to property, and verbal aggression. The program lasted for two years and included the study of relaxation, self-control, role-playing games and more. The results obtained a year after the start of intervention showed a reduction in feelings of anger. Benbenishty et al., (2007) report on the availability of a wide range of programs and intervention services in the United States aimed at preventing violence. The programs include counseling services, crisis intervention, teaching skills, and peer programs for students, community programs and more. Interventions such as dismissals, suspension for a limited time period, and transfer to a special education school are common responses to occurrences of school violence.
The primary aim of this study was to assess the impact of an intervention program based on previous research that used the model of the "Cycle of Internalized Learning" or CIL model (Reiter, 2008). This program is based on a humanistic paradigm that emphasizes the importance of the group in nurturing individual and interpersonal abilities of the students to live a creative, productive, self-fulfilled and satisfied life (Reiter, 2008; Reiter \& Schalock, 2008).

The group intervention program that was implemented in this study was not specifically designed to prevent violence, but was found to be fully suitable for dealing with verbal violence.

The stages of the model are: A. Opening Stage Introduction of the Subject: the teacher introduces the subject chosen for learning by referring to two sources, the learners' world and needs, and the school curriculum. The teacher encourages students to raise relevant personal experiences and associations. Their response is subjective and concrete. At this stage, they express an initial, albeit scattered, personal awareness; B. Discussion/Lesson: a lesson takes place, whereby the teacher clarifies with the students concepts, definitions, and generalities. This is done by isolating and defining the different components of the subject matter, as it relates to the participants' experiences. Social skills, cultural norms and values are also learned during this stage. C. Open conversation: the subject raised during the first meeting is now reviewed. The teacher encourages the students to relate to themselves and others in a critical manner according to concepts and skills learnt in stage B. At this stage, the students are invited to suggest new solutions to the issues and problems raise in the opening stage. D. Repeat Experience: it is recommended to make this stage the active part of learning, by going out on a field trip or performing role play. In this way there is a review of the subject learned by incorporating the change and solutions suggested by the group members; E. Repeat Discussions: following the actual experience, a repeated group discussion is conducted to gain new insights regarding the subject meter. The teacher encourages the participants to form an autonomous perspective and to recognize their own priorities, i.e., "What is more and what is less important to me?", "Did I learn new things about myself and about my friends?"; F. Outcomes: finally the teacher evaluates the process outcomes according to the extent that the students show that they apply personal and autonomous criteria of judgment in the evaluation of their life experiences and are able to make personal choices among alternatives. Outcomes are assessed in the following areas: personal autonomy, enriched knowledge and new skills (Reiter, 2008, p.185).

The decision to test the effectiveness of the CIL in reducing verbal violence among 12-16 year-olds was made because this age group has been shown to have the highest rates of violence (Wang, Iannotti, \& Nansel, 2009).

To examine the effectiveness of the intervention program, the following hypothesis were addressed:

1. Significant differences will be found between boys 
and girls use of verbal violence, wilt the girls having a greater tendency to use verbal violence.

2. The use of verbal violence among the students taking part in the experimental group will be reduced following the intervention program.

\section{Method}

\subsection{Participants}

The target population chosen for this study were middle school students with moderate ID attending a special education school. Moderate intellectual disability (IQ 3549 ) is nearly always apparent within the first years of life. Speech delays are particularly common signs of moderate ID. People with moderate intellectual disability need considerable supports in school, at home, and in the community in order to enable them to fully participate (Daily, Ardinger, Holmes, 2000).

The students in this study were chosen from a special education areal school in Northern Israel where classes are small with about $8-10$ students. Each class has a teacher and a teacher's aide. The total student population at the school was 80 . The students came from a large geographical area, including many from new immigrant families in low socioeconomic neighborhoods.

Out of the 80 students, 44 students were chosen for the study because they were in the five classrooms that were chosen by the school principal who took into consideration the students capability and the size of the classes. In order to get approximately equal numbers of students in each condition, three classrooms were the experimental group (N $=20)$ and two classes were the comparison group $(\mathrm{N}=24)$. They included 25 girls and 19 boys aged between of 12 to 16 (with a mean age of 14.7).

\subsection{Instrument}

Questionnaire: Students were asked to complete a questionnaire that assessed the level of use of verbal violence based on the questionnaire of bullying developed by Olweus (1993). The questionnaire was used to gather information on the pattern and level of verbal violence. It is based on items such as "Did you use verbal violence against another student during the last week in the school?" with a response scale from 1 (never) to 5 ( 5 times or more). The 21 items of the questionnaire include five subscales presented in Table 1. Cronbach's alpha across the whole survey was 0.88 .

Table 1. Subscales of the questionnaire

\begin{tabular}{|c|c|c|c|c|}
\hline & Subscales & Examples & Items & Cronbach's alpha \\
\hline A & $\begin{array}{l}\text { "Experience of Verbal Violence" (items that } \\
\text { represent name calling, verbal threats etc.,) }\end{array}$ & $\begin{array}{l}\text { "Have other students threatened to hurt you?" } \\
\text { or "Have other students cursed you?" }\end{array}$ & $12-15$ & 0.86 \\
\hline B & $\begin{array}{l}\text { "Loneliness" (items that represent lack of } \\
\text { friends, loneliness in break time and in school } \\
\text { in general, social acceptance failure, etc.,) }\end{array}$ & $\begin{array}{l}\text { "Do you feel lonely at school?", "Did other } \\
\text { students not want to be with you at break } \\
\text { time?" }\end{array}$ & $2-6$ & 0.88 \\
\hline $\mathrm{C}$ & $\begin{array}{l}\text { "Bothering" (items that represent harassment, } \\
\text { bulling etc.,) }\end{array}$ & "Have you been insulted in the school?" & $7-10$ & 0.81 \\
\hline D & $\begin{array}{l}\text { "Social treatments" (items that represent } \\
\text { verbal force etc.,) }\end{array}$ & $\begin{array}{l}\text { "Have students shouted at you?" and "Have } \\
\text { students humiliated you?" }\end{array}$ & $1,11,16,17$ & 0.66 \\
\hline $\mathrm{E}$ & $\begin{array}{l}\text { "Use of Verbal Violence" (items that represent } \\
\text { swearing etc.,) }\end{array}$ & $\begin{array}{l}\text { "Do you curse other students at school?" and } \\
\text { "Do you think it's fun to bully others?" }\end{array}$ & $18-21$ & 0.86 \\
\hline
\end{tabular}

\subsection{Procedure}

In the $1^{\text {st }}$ Phase, approval of the study was obtained from the Chief Scientist of the ministry of education, and the school administration. Next, the principal identified the classrooms where the study would take place and the parents of all the students in these classrooms received written information on the research objectives and procedures and gave their written signed consent for their child to participate in the study. Prior to starting the intervention the students in both conditions completed the Olweus bulling questionnaire (1993) individually. Whenever a student had difficulties with answering an item the homeroom teacher assisted him/her.

In the $2^{\text {nd }}$ Phase the group intervention program was implemented in the experimental groups. The comparison groups continued to learn in accordance with the regular school program. Their classrooms was not taught any subject content related to violence. The intervention program consisted of five lessons (50 minutes each) over a period of five weeks. The program was an innovative one for the grade teachers. For this reason they underwent special training with an expert on the "Cycle of Internalized Learning" model. The CIL was applied by the teacher with the whole classroom. The purpose of the program was to examine whether it will be effective in reducing the use of verbal violence among students with moderate Intellectual Disability (MID). The first lesson dealt with definitions of physical and verbal violence and the distinction between the two types of violence; The second lesson focused on insults and name calling; The third lesson discussed swearing and racist remarks; The fourth lesson discussed shouting and humiliating comments; the fifth lesson was divided in to two parts - threats and intimidation and a summary of all types of verbal aggression.

The following example presents the way the variables of 
insult and name calling, were presented to the students according to the five stages of the CIL: A. Opening Stage Introducing the Subject. The teacher tells a story to the students about a group of children playing soccer. "A boy named Danny misses a goal. Danny was overweight. The other kids start to tell him 'you are chubby and that's the reason you can't move', ' It is better for you not to play' and so on. B. Discussion/Lesson - The teacher checks with the students to make sure they understand what has happened and how it is an example of insults and name calling. C. Open conversation - this part is dedicated to raising the students' personal experiences with insults and name calling, and their analysis. They discuss how the other children negatively reacted against Danny as well as their own experiences and stories. The students suggests alternative ways to respond to the situation. D. Repeat Experience - here the students go back to the case description with Danny apply their proposed changes in the childrens' behavior. They role play how they might react. E. Repeat Discussions - the students demonstrated their insights in to alternative ways for appropriate behavior in social conditions. F. Outcomes - in the second part of the fifth lesson, students expressed their new perceptions on verbal violence.

The $3^{\text {rd }}$ Phase occurred one month after the end of the program when we re-administered our measures to students in both the experimental and comparison groups.

\section{Results}

To test the hypothesis about possible differences between boys $(\mathrm{N}=19)$ and girls $(\mathrm{N}=25)$ in the pattern of use of verbal violence, with the girls having a greater tendency to use verbal violence, a $\mathrm{T}$ test was conducted on the whole sample at baseline. The findings are presented in Table 2 .

Table 2. comparison between boys and girls in using verbal violence

\begin{tabular}{lllll}
\hline Gender & $\mathbf{N}=\mathbf{4 4}$ & Mean & Standard Deviation & $\mathbf{t ( 4 2 )}$ \\
\hline Boys & 19 & 7.95 & 3.96 & -1.41 \\
Girls & 25 & 9.64 & 3.90 & \\
\hline
\end{tabular}

$* \mathrm{p}>0.05$

The data presented in the table shows that there are no significant statistical differences between boys and girls in their use of verbal violence [ $\mathrm{t}(43,1)=-1.41, \mathrm{p}>0.05]$, although the girls have a greater tendency to use verbal violence $(\mathrm{M}=9.64, \mathrm{SD}=3.90)$ compared to the boys $(\mathrm{M}=7.95, \mathrm{SD}=9.96)$.

To test the hypothesis that claims that the use of verbal violence among the students taking part in the experimental group will be reduced following the intervention program, a repeated measures ANOVA was conducted. Results are presented in Table 3 and Figure 1.

Table 3. Experience of Verbal Violence: Averages and Standard Deviations

\begin{tabular}{|c|c|c|c|c|c|c|c|}
\hline & \multicolumn{2}{|c|}{ Experiment $* \mathbf{N}=\mathbf{2 0}$} & \multicolumn{2}{|c|}{ Control N=24 } & \multicolumn{2}{|c|}{ Total $N=44$} & \\
\hline & Average & S.D. & Average & S.D. & Average & S.D. & \\
\hline Before & 10.00 & 3.30 & 9.67 & 3.38 & 9.82 & 3.31 & $\begin{array}{l}* \mathrm{~F}(1,42)=15.182 \\
\mathrm{Eta}^{2}=0.26\end{array}$ \\
\hline After & 6.55 & 2.32 & 9.75 & 3.49 & 8.29 & 3.39 & $p<0.005$ \\
\hline
\end{tabular}

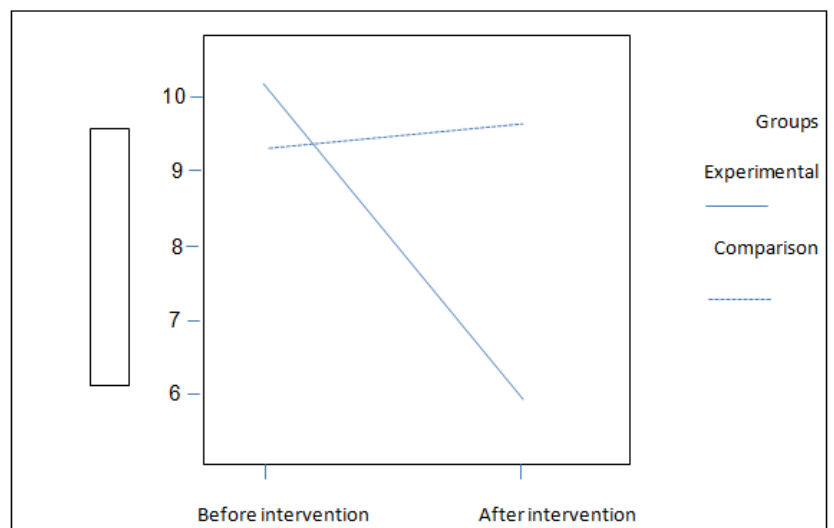

Figure 1. Estimated Marginal Means of Verbal Violence.

The experimental $(\mathrm{M}=10.00 ; \mathrm{SD}=3.30)$ and control $(\mathrm{M}=9.67 ; \mathrm{SD}=3.38)$ groups did not differ in their experience of verbal violence at baseline. After the intervention, students in experimental condition had a significant reduction in using verbal violence $(M=6.55$; $\mathrm{SD}=2.32$ ) while no change was seen in the control group
$(\mathrm{M}=9.75 ; \quad \mathrm{SD}=3.49)$. The difference was statistically significant $(\mathrm{DF}(1,42)=15.182, \mathrm{p}<0.005)$.

\section{Discussion}

Violence and aggression behaviors are a key part of antisocial behaviors. Violence is a widespread problem in schools and occurs in many countries all over the world (Balin-Arcaro, et al., 2012; Douma, Dekker, Ruiter, \& Tick 2007; Lund, et al., 2012).

This study is the first to examine verbal violence among students with ID. Characteristics of verbal violence that emerged from the research literature (Olweus, et al., 1999; Uzun, 2003) and from this study were: mockery (reported by $46 \%$ of the students), swearing (reported by $56 \%$ of the students), name-calling (reported by $21 \%$ of the students), boycotts(reported by $21 \%$ of the students), shouting (reported by $44 \%$ of the students), insults (reported by $34 \%$ of the students), humiliation (reported by $32 \%$ of the students), intimidation (reported by $48 \%$ of the students), threats (reported by $54 \%$ of the students), racist remarks 
(reported by $16 \%$ of the students) and other expressions whose purpose is to harm a particular person and any other violent behavior that has a verbal aspect (reported by $23 \%$ of the students).

The ultimate goal of this study was to create an intervention program, among students with Moderate intellectual disability that will reduce the use of verbal violence. To examine this phenomenon, a group intervention program was activated designed to change the verbalization from one having a violent nature to a nonviolent one. Indeed, in this study the level of use of verbal violence has decreased following the intervention program. After the intervention, the experimental group reported on engaging in less verbal violence over time compared to those in the comparison group.

The first hypothesis of this research deals with gender differences in the use of verbal violence. It was assumed that girls will make more use of verbal violence compare to boys.

Some research has shown that girls are more involved in verbal violence compare to boys (Balin-Arcaro, et al., 2012; Benbenishty et al., 2007; Eaton, et al., 2008). However, other studies (e.g., Liang et al., 2007) found no differences by gender. In this study there were no significant differences observed between the groups, although the girls had greater tendency to use verbal violence then the boys.

In this study it was found that students who had participated in the intervention program reported over time on engaging less in verbal violence. They learned in the program how to identify and to cope with situations that have a violent nature. The intervention operated in the current study is based on the CIL (Reiter, 2008, p.185) and mainly through discussions with students, encouraging students to share and report violent behaviors, and providing tools for dealing with situations of violence. This finding, similar to the findings of other studies, shows that the most effective programs to prevent violence needs to be based on positive behavior support with the focus being on conversations with students (Sherer \& Nickerson, 2010; Lund et al., 2012). In addition Reiter's (2008) ecological model claims that people with disabilities fear intimate relationships. They have a negative self-image, they grow up with social skills deficits and with negative social experiences. But all of this can be changed - by running intervention programs in social education, aimed at strengthening the individual with a disability. From this, in the current study an intervention program was implemented intended to reduce the use of verbal violence as a way of strengthening individuals with ID, giving them tools to deal with social situations in a non-violent way.

\subsection{Other Interesting Findings}

Findings from the Benbenishty and his colleagues' research (2003) among 5267 students without disabilities show that the use of verbal violence is the most common manifestation of violent behavior among the students. $48.1 \%$ of the students reported that other student had cursed them three times or more in the previous month. $32.7 \%$ of the students reported that other student mocked, insulted or humiliated them. About half of the students (48.4\%) reported that other student threatened at least once to hurt or to beat them.

In the current study $45 \%$ of the students reported that they often suffer from verbal violence. $30 \%$ of the students reported about suffering from bulling, 36\% reported about being socially threatened, and $30 \%$ reported about loneliness at the school. We can claim that children with ID use and are exposed to verbal violence to the same extent as children without disabilities.

\subsection{Implications of these Findings for Policy, Programs, and Future Research}

From a theoretical aspect, the contribution of the current research in the field of verbal violence among students with ID is that it is a pioneer subject of interest to professionals, educators and it has become a public issue. The field of violence in general and in particular the use of verbal violence among students with disabilities has only just recently increased academic and public awareness. From an applied perspective, the research has educational implications and the study findings provide information that contribute to the understanding of patterns of interpersonal relations among students with ID and in the design of future intervention programs.

Since this was a preliminary study, there are several questions that must be examined and studied further; a wider study will provide a more accurate picture of the relationship between loneliness and verbal violence. The differences between boys and girls should be examined in a wider population. In addition, further research should focus on the following issues:

Will a reduction in the use of verbal violence expressions weaken or increase physical violence?

Related intervention programs aimed at reducing and preventing violence in schools, have not yet completed. Comprehensive studies on the extent of use of various intervention programs needed to deal with verbal violence in schools have to be undertaken.

\subsection{Study Limitations}

The main purpose of this study was to investigate the degree of usage of verbal violence among students with MID. An additional purpose was to find out if an intervention program has an influence and effect on reducing the level of verbal violence. The study focused on only one school and therefore the conclusions drawn are only a significant initial preliminary stage in a much wider needed study. Hence, we can say that there may be difficulties in making generalization. Further, another limitation may be the sample size. For example, in the examination of the differences between boys and girls in the use of verbal violence there were no significant differences found, although it was discovered that girls had 
greater tendency. Thus in order to be able make such generalization a larger research, with more participants involved may need to be conducted for.

\subsection{Summary}

In summary, implications arising from this study and from previous studies, suggest that coping with inappropriate social interactions lead the subjects to the use of verbal violence as an expression of social communication. It is designed to create social relations, to achieve personal goals in social interactions and to respond to these situations. Effects of group intervention program activated in social situations relate to the benefits arising from the use of such a program and the resulting social implications.

\section{References}

[1] Balin-Arcaro, C., Smith, J.D., Cunningham, C.E., Vaillancourt, T., \& Rimas, H. (2012). Contextual attributes of indirect bullying situations that influence teachers' decisions to intervene. Journal of School Violence, 11, 226-245.

[2] Benbenishty, R., Astor, R. (2005). School violence in context :Culture, neighborhood, family, school and gender. New York: Oxford.

[3] Benbenishty, R., Astor, R., Marachi R. (2007). Effects of Student Participation and Teacher Support on Victimization in Israel Schools: An Examination of Gender, Culture, and School Type. Journal Youth Adolescence, 36, 225 - 240.

[4] Benbenishty, R., Astor, R., \& Zeira, A., (2003). Monitoring school violence on the site level: Linking national-, district-, and school-level data over time. Journal of School Violence 2, 29-50.

[5] Bernes B.K., \& Bardick D.A., (2007). Conducting Adolescent Violence Risk Assessment: A Framework for School Counselors. ASCA. Professional school counseling, p. $419-427$.

[6] Carter, B., \& Spencer, V. (2006). The Fear Factor: Bulling and Students with Disabilities. International Journal of Special Education, 21, 11 - 23.

[7] Craig, W. M., \& Pepler, D. J. (2007). Understanding bullying: From research to practice. Canadian Psychology, 48, 86-93.

[8] Daily, D., Ardinger, H., Holmes G. (2000). Identification and Evaluation of Mental Retardation. American Family Physician, 15, $1059-1067$.

[9] Douma, J.C.H., Dekker, M.C., Ruiter, P.K., \& Tick, T.N., (2007). Antisocial and Delinquent Behavior in Youths with Mild or Borderline Disabilities. American Journal on Mental Retardation, 112, 207 - 220.

[10] Eaton, D.K., Kann, L., Kinchen, S., Shanklin, S., Ross, J., Hawkins, J., et al. (2008). "Youth risk behavior surveillance-United States, 2007". Morbidity and Mortality Weekly Report. Surveillance Summaries/CDC [MMWR Surveill Summ] 57 (4): 1-131. PMID 18528314. http://www.cdc.gov/mmwr/preview/mmwrhtml/ss5704a1.ht m.

[11] Estell, D.B., Farmer, T.W., Irvin, M.J., Crowther, A., Akos, P., Boudah, D.J. (2009). Students with Exceptionalities and the Peer Group Context of Bullying and Victimization in Late Elementary School. Journal of Child and Family Studies 18, 136 - 150.

[12] Evans, P. (2010). The verbally abusive relationship: How to recognize it and to respond $\left(3^{\text {rd }} \mathrm{ed}\right)$. Avon, MA: Adams Media.

[13] Evans, P. (2012). Victory over verbal abuse: A healing guide to renewing your spirit and reclaiming your life. Avon, MA: Adams Media.

[14] Grossman, D.C., Neckerman, H.J., Koepsell, T.D., Liu, P.Y, Asher, K.N., Beland, K., et al. (1997). Effectiveness of a violence prevention curriculum among children in elementary school: A randomized controlled trial. Journal of the American Medical Association, 277, 1605 - 1611.

[15] Krakowski, M., Czobor, P. (2004). Gender Differences in Violent Behaviors: Relationship to Clinical Symptoms and Psychological Factors. The American Journal of Psychiatry, $161,459-465$.

[16] Liang, H., Flisher, J.A., Lombard J.C. (2007). Bullying, violence, and risk behavior in South African school students. Child Abuse \& Neglect 31, 161 - 171.

[17] Lund, M., Blake, J.J., Ewing, H.K., \& Banks, C.S. (2012). School Counselors' and School Psychologists' Bullying Prevention and Intervention Strategies: A Look into RealWorld Practices. Journal of School Violence, 11, 246 - 265

[18] Nansel, T., Overpeck, M., Pilla, R.S., Ruan, W.J., Simmons Morton, B., Schmidt, P. (2003). Bullying Behaviors among US youth. Journal of American Medical Association, 285, $2094-2100$.

[19] Olweus, D. (1991). Bully/victim problems among schoolchildren: Basic facts and effects of a school based intervention program. In D. J. Pepler \& K. H. Rubin (Eds.). The development and treatment of childhood aggression (pp. 411 - 448). Hillsdale, NJ: Lawrence Erlbaum.

[20] Olweus, D. (1993). Bullying at school: What We Know and What We Can Do. Oxford UK: Blackwell Publishers.

[21] Olweus, D., Limber, S., \& Mihalic, S.F. (1999). Blueprints for violence prevention, book nine; bullying prevention program. Boulder, CO; Center for the study and Prevention of violence.

[22] Reiter, S. Bryen, D. Shachar, Y. (2007). Adolescents with intellectual disabilities as victims of crimes. Journal of Intellectual Disability Research, 11, 1 - 17. Impact Factor 1.068

[23] Reiter, S. (2008). Disability from a humanistic perspective: Towards a better quality of life. New York: Nova Science Publishers Book Series: Health and Human Development (p. 237)

[24] Reiter, S. \& Lapidot-Lefler, N. (2007) Bullying Among Special Education Students With Intellectual Disabilities: Differences in Social Adjustment and Social Skills. Intellectual and Developmental Disabilities: June 2007, 45, 174-181. 
[25] Reiter, S., Schalock, R. L. (2008). Applying the concept of quality of life to Israeli Special Education programs: A national curriculum for enhanced autonomy in students with special needs. International Journal of Rehabilitation Research, 31, 13 - 21. . Impact Factor 0.5

[26] Ross, J., West, C. \& Clifford, D. (2000) Group interventions for anger in people with intellectual disabilities. Research in Developmental Disabilities 21, 171 - 181.

[27] Schalock, R.L., Borthwick-Duffy, S.A., Bradley, V.J., Buntinx, W., Coulter, D.L., Craig, E.M., et al. (2010). Intellectual Disability: Definition, Classification, and Systems of Supports (11th Edition). American Association on Intellectual and Developmental Disabilities (AAIDD).

[28] Sherer, Y. C., \& Nickerson, A. B. (2010). Anti-bullying practices in American schools: Perspectives of school psychologists. Psychology in the Schools, 47, 217-229.
[29] Sigafoos J., Elkins J., Kerr M. \& Attwood T. (1994) A survey of aggressive behavior among a population of persons with intellectual disability in Queensland. Journal of Intellectual Disability Research 38, 369 - 381.

[30] Uzun, O. (2003). Perceptions and experiences of nurses in Turkey about verbal abuse in clinical settings. Journal of Nursing Scholarship 35, $81-85$.

[31] Wang, J., Iannotti, R. J., \& Nansel, T. R. (2009). School bullying among adolescents in the United States: Physical, verbal, relational, and cyber. Journal of Adolescent Health, 45, 368-375. doi:10.1016/j.jadohealth.2009.03.021 